\title{
Population genetics of the brooding coral Seriatopora hystrix reveals patterns of strong genetic differentiation in the Western Indian Ocean
}

\author{
Rosa M. van der Ven $\mathbb{\circledR}^{1,2} \cdot$ Jean-François Flot $\mathbb{1}^{3} \cdot$ Carol Buitrago-López $\mathbb{\circledR}^{1,4} \cdot$ Marc Kochzius ${ }^{1}$
}

Received: 20 June 2019 / Revised: 6 October 2020 / Accepted: 7 October 2020 / Published online: 29 October 2020

(c) The Author(s), under exclusive licence to The Genetics Society 2020

\begin{abstract}
Coral reefs provide essential goods and services but are degrading at an alarming rate due to local and global anthropogenic stressors. The main limitation that prevents the implementation of adequate conservation measures is that connectivity and genetic structure of populations are poorly known. Here, the genetic diversity and connectivity of the brooding scleractinian coral Seriatopora hystrix were assessed at two scales by genotyping ten microsatellite markers for 356 individual colonies. $S$. hystrix showed high differentiation, both at large scale between the Red Sea and the Western Indian Ocean (WIO), and at smaller scale along the coast of East Africa. As such high levels of differentiation might indicate the presence of more than one species, a haploweb analysis was conducted with the nuclear marker ITS2, confirming that the Red Sea populations are genetically distinct from the WIO ones. Based on microsatellite analyses three groups could be distinguished within the WIO: (1) northern Madagascar, (2) south-west Madagascar together with one site in northern Mozambique (Nacala) and (3) all other sites in northern Mozambique, Tanzania and Kenya. These patterns of restricted connectivity could be explained by the short pelagic larval duration of S. hystrix, and/or by oceanographic factors, such as eddies in the Mozambique Channel (causing larval retention in northern Madagascar but facilitating dispersal from northern Mozambique towards south-west Madagascar). This study provides an additional line of evidence supporting the conservation priority status of the Northern Mozambique Channel and should inform coral reef management decisions in the region.
\end{abstract}

\section{Introduction}

Coral reefs provide habitat for at least a quarter of all known marine species (Fisher et al. 2015) and sustain an estimated value of around US\$352,000 ha $\mathrm{h}^{-1}$ of ecological goods

Associate editor: Rui Faria

Supplementary information The online version of this article (https:// doi.org/10.1038/s41437-020-00379-5) contains supplementary material, which is available to authorised users.

Rosa M. van der Ven

Rosa.vanderven@gmail.com

1 Marine Biology, Ecology and Biodiversity, Vrije Universiteit Brussel (VUB), Brussels, Belgium

2 School of Life Sciences, University of Essex, Colchester, UK

3 Evolutionary Biology \& Ecology, Université libre de Bruxelles (ULB), Brussels, Belgium

4 Red Sea Research Center (RSRC), King Abdullah University of Science and Technology (KAUST), Thuwal, Saudi Arabia and services such as food, coastal protection and recreation (Costanza et al. 2014). Currently, coral reef degradation is occurring at an alarming rate due to a variety of local and global anthropogenic stressors (Hoegh-Guldberg et al. 2017). The main limitation that prevents the implementation of adequate conservation measures is that the connectivity and genetic structure of coral populations are poorly known. Resilience-based management, such as marine protected area (MPA) networks, aims to support coral reefs by maximising reef resistance and recovery to environmental changes, but in order to be effective, knowledge of the connectivity among reefs is essential (McLeod et al. 2019). Connectivity determines gene flow and subsequently the genetic diversity and genetic structure of populations: for instance, high connectivity can facilitate the restoration of heavily disturbed or degraded sites (Palumbi 2003; van Oppen and Gates 2006). As adult corals are sedentary, connectivity between reefs is established through dispersal of larvae. Therefore, traits such as the pelagic larval duration (PLD) and larval behaviour have been proposed to be crucial determinants of genetic population structure. 
Additionally, dispersal is also constrained by environmental conditions, such as currents, oceanographic barriers and habitat suitability for larval settlement (Baird 2001; Cowen and Sponaugle 2009).

Larvae in scleractinian corals result mostly from sexual reproduction, which can broadly be divided in two strategies: broadcast spawning and brooding (Harrison 2011). Broadcast spawning corals release buoyant gamete bundles with eggs and sperm to the water column, where fertilisation and subsequent embryonal development take place. In brooding corals, only sperm is spawned, often during several months, with subsequent internal fertilisation and development of the larvae. Brooding corals are generally assumed to have a shorter PLD and consequently higher levels of genetic subdivision than found in broadcast spawning corals, but current evidence for this is limited. For example, the brooding coral Seriatopora hystrix was found to exhibit predominantly short-distance dispersal in Australia, where larvae mainly settled close to their natal colony (Underwood et al. 2007, 2009; van Oppen et al. 2008), and isolation by distance was found in the Red Sea on a small geographic scale (within $20 \mathrm{~km}$, Maier et al. 2005). At the same time there is also evidence for occasional longdistance dispersal on reefs in Australia (Underwood et al. 2007; van Oppen et al. 2008).

Reproduction and connectivity form an integral component of studies on the long-term dynamics of coral species (e.g., McLeod et al. 2019; van Oppen and Gates 2006). However, unrecognised interspecific diversity, or cryptic diversity, challenges our understanding of connectivity patterns (Sheets et al. 2018). Morphospecies of scleractinian corals often do not correspond to "biological" species, particularly for corals with high morphological plasticity such as acroporids (Richards et al. 2016) and pocilloporids (e.g., Flot et al. 2010), including Seriatopora (Flot et al. 2008; Nakajima et al. 2017; Warner et al. 2015). Adding to the difficulty of resolving relationships, highly permeable reproductive boundaries have been described between some morphospecies of scleractinian corals (e.g., Vollmer and Palumbi 2002). This complicates current attempts to define spatial units of conspecific corals that exchange alleles. Such metapopulations could be used as units in conservation planning, but it is still unknown to what extent widespread coral morphospecies represent metapopulations that regularly exchange genetic material or form isolated subsets of populations (or even cryptic species). For all these reasons, species delimitation in corals requires comprehensive approaches that integrate molecular, morphological and distributional data (Schmidt-Roach et al. 2014; Arrigoni et al. 2020). In the case of cnidarians, the cytochrome $c$ oxidase subunit I fragment typically used for DNA barcoding of animals is not variable enough to distinguish most species (Shearer and Coffroth 2008). Even when more variable mitochondrial regions are available, as in the case of pocilloporid corals (Flot and Tillier 2007), mitochondrial markers, unlike nuclear markers, are haploid and can therefore only be analysed using distance-based and tree-based approaches (Flot 2015). The former assumes that intraspecific distances are smaller than interspecific ones, while the latter only detect species that are monophyletic (Fontaneto et al. 2015), two requirements that are not always met for coral species, because of their large effective population sizes and the possible occurrence of hybridisation. Nuclear markers, by contrast, can be analysed using tree-based, distance-based, as well as allele sharing-based methods (Fontaneto et al. 2015). Allele sharing-based methods such as haplowebs (Flot et al. 2010) can help delimiting species regardless of their monophyly (or lack thereof). Like other single-locus methods, haplowebs may be confounded by markers under selection or in case of recent introgression and shared ancestral sequences (Flot et al. 2010). However, simulation studies have shown that haplowebs tend to perform better than other approaches designed to infer which individuals in a data set are conspecific (Dellicour and Flot 2015, 2018), providing useful information for the implementation of adequate management of coral populations.

The coral reefs of the Western Indian Ocean (WIO) and the Red Sea offer a unique environment to study the connectivity of corals under variable environmental conditions along a north-south gradient covering $\sim 6000 \mathrm{~km}$. The WIO has fringing reefs along almost the entire African coast, and these reefs experience complex oceanographic conditions (Fig. 1): the South Equatorial Current (SEC) carries water westwards towards the southern coast of Tanzania and the northern coast of Mozambique, where it bifurcates southward into the eddies in the Mozambique Channel down to South Africa and northward into the East African Coast Current (EACC) along the coasts of Tanzania and Kenya (Hancke et al. 2014; Lutjeharms and Bornman 2010; Schott and McCreary 2001; Sofianos and Johns 2003). Connected through the shallow and narrow strait of Bab-el-Mandeb with the Gulf of Aden, the Red Sea is a peripheral region of the Indo-Pacific that is characterised by a high coral biodiversity. Currents in the Red Sea are formed by gyres and these circulation patterns are spatially and temporally variable (Sofianos and Johns 2003). Based on coral species diversity, three regions can be distinguished in the central WIO (Obura 2012): the reefs surrounding the Northern Mozambique Channel (NMC region) that form the highdiversity core region in the WIO, the East African Coast (EAC) region that is under the influence of the EACC, and the Southern Mozambique Channel region (SMC) under the influence of Mozambique Channel eddies (Fig. 1). To date, 


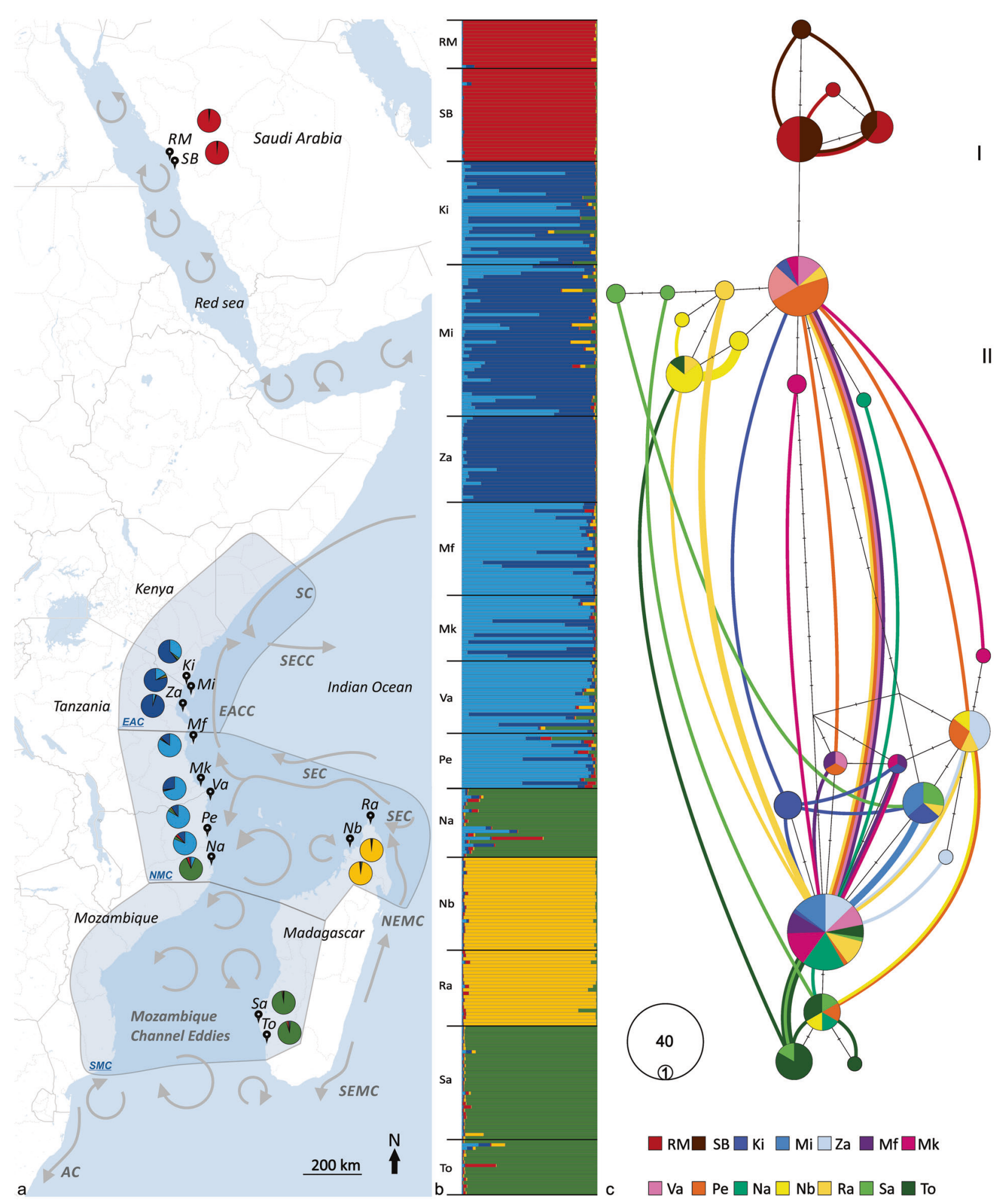

studies on coral connectivity patterns within or between major biogeographical regions of the WIO and the Red Sea are not available, as research tends to be limited to smaller geographical scales. S. hystrix (Pocilloporidae; Dana 1846) is an ideal species for such study as it has a widespread distribution in the Indo-Pacific, occurring, e.g., in the Red
Sea, Madagascar, along the coast of East Africa in Kenya and Tanzania, as well as in the north and south of Mozambique (Veron 2000). It is common not only on shallow reefs and intertidal reef flats, but also at mesophotic depths (Prasetia et al. 2017; van Oppen et al. 2011; Veron 2000). S. hystrix is a brooding coral that releases planula 
Fig. 1 Sample sites and spatial genetic structure of the stony coral Seriatopora hystrix. a Map showing sample sites of S. hystrix in Saudi Arabia, Kenya, Tanzania, Mozambique and Madagascar. Major ocean currents during the Northeast Monsoon are indicated schematically (Collins et al. 2014; Hancke et al. 2014; Lutjeharms and Bornman 2010; Schott and McCreary 2001; Sofianos and Johns 2003). SEC South Equatorial Current, NEMC Northeast Madagascar Current, SEMC Southeast Madagascar Current, EACC East African Coast Current, SECC South Equatorial Counter Current, SC Somali Current, AC Agulhas Current. Biogeographic regions proposed by Obura (2012) are also indicated: EAC East African Coastal region, NMC Northern Mozambique Channel region, SMC Southern Mozambique Channel region; sample site codes: RM Ras Masturah, SB Shi'b Al Bayda, Ki Kisite, Mi Misali, Za Zanzibar, Mf Mafia, Mk Mikindani, Va Vamizi, Pe Pemba, Na Nacala, Nb Nosy Be, Ra Ramena, Sa Salary; To Toliara. The pie charts show the distribution of five genetic clusters $(K=5)$ at sample sites as revealed by the Bayesian clustering implemented in STRUCTURE 2.3.4 (Pritchard et al. 2000). b Bar plot showing estimated membership fractions in each of the five clusters, with each horizontal bar representing one individual. c Haplotype network (haploweb) based on 124 sequences of the ITS2 marker. Each pie chart represents one of the 24 haplotypes, its area proportional to the number of individuals in which it was found and with colours indicating the locations where it was sampled. Black lines show the mutational steps between haplotypes. Coloured curves connect haplotypes that co-occur within heterozygous individuals: the thickness of a curve connecting two haplotypes represents the number of individuals in which these haplotypes co-occur, with colours indicating the locations where these individuals were sampled. Within this haploweb two groups are distinguished in which all haplotypes are connected by heterozygotes: group I includes all individuals collected in the Red Sea and group II includes all individuals collected in the Western Indian Ocean.

larvae year-round in the tropics and has a short PLD ranging from $6-12 \mathrm{~h}$ to 1 week in aquarium experiments (Baird 2001; Isomura and Nishihira 2001; Prasetia et al. 2017). Due to its short PLD, the brooding coral S. hystrix is a good model species to investigate the influence of ocean currents on the dispersal of reef building corals. This study investigates the genetic diversity, population structure and connectivity patterns of the brooding coral $S$. hystrix at two different scales: first, by comparing the WIO and the Red Sea, and second, by comparing sites within the WIO. Based on the life history of S. hystrix, species richness distribution and ocean currents (discussed in Obura et al. 2019), the hypotheses we aimed to test were: (1) a genetic break separates the Red Sea and the WIO, (2) the NMC region is genetically distinct and characterised by a high genetic diversity, (3) the SMC region is genetically distinct and (4) a genetic break occurs between the NMC and EAC regions. The four hypotheses were tested using ten microsatellite markers and a complementary haploweb analysis of the nuclear ITS2 marker, a strategy also used by Adjeroud et al. (2014). Ultimately, we hope that this study provides important insights into the genetic structure of coral populations and the possible link between PLD and oceanography, as well as reveal which spatial scales are relevant for conservation initiatives.

\section{Material and methods}

\section{Study region and sampling}

The WIO has fringing reefs along the coast, with patchier reefs in the north of Kenya that become more extensive and diverse southwards into Tanzania and then into the north of Mozambique (McClanahan et al. 2014; Obura 2012; Obura et al. 2017). There are smaller and patchier offshore reefs in the South of Mozambique (Motta et al. 2002; Ridgway et al. 2008), but they are separated from the northern reefs by an area devoid of coral reefs, because of freshwater discharge and sediments from the large-scale river outlets and mangrove forests of central Mozambique (Obura et al. 2017). Across the channel, the Madagascar coastline consists of many fringing and barrier reefs as well as banks separated by extensive mangrove forests (Obura et al. 2017). The Red Sea has mainly fringing reefs along most of both shores, with atolls and pinnacle reefs found in the southern and central Red Sea (Wilkinson 2002). A total of 356 individual $S$. hystrix colonies were sampled at two locations in Saudi Arabia and 12 locations in the WIO: one in Kenya, four in Tanzania, three in Mozambique and four in Madagascar (Fig. 1a and Appendix S1). It is important to note that in this study no $S$. hystrix colonies were found in Mozambique south of Nacala (for which the sampling campaign included Vilanculos, Pembane, Tofo, Xai-Xai, Inhaca and Ponta do Ouro). Colonies were randomly selected within a reef with a distance of at least $2 \mathrm{~m}$ between consecutive collections, in order to reduce the chances of sampling clones. Each sample was obtained by cutting a $2-3 \mathrm{~cm}$ fragment from a branch. The fragments were stored in a plastic container with seawater until fixation in absolute ethanol. Samples were stored in the dark at $7{ }^{\circ} \mathrm{C}$ until extraction.

\section{DNA extraction and microsatellite genotyping}

Fragments were cut manually into small pieces with a wire cutter and DNA was extracted following the animal tissue protocol Omega Bio-tek ${ }^{\circledR}$ E.Z.N.A. ${ }^{\circledR}$ Tissue DNA kit (Norcross, GA, USA) to a final volume of $100 \mu \mathrm{L}$. Samples were genotyped using ten microsatellite primer pairs designed for S. hystrix from the Red Sea and Australia (details of the DNA extraction, primers and PCR conditions given in Appendix S2). PCR products were analysed on an ABI 3730 DNA Analyzer (Applied Biosystems, Foster City, CA, USA). The resulting electropherograms were scored manually using GeneMarker ${ }^{\circledR}$ (v. 2.6.0; SoftGenetics, State College, PA, USA). 


\section{Genetic diversity analysis}

The software GenAlEx 6.503 (Peakall and Smouse 2012) was used to determine the probability of identity (PI) and to identify identical multilocus genotypes that were likely to be the result of fragmentation of the coral colony. Departures from Hardy-Weinberg equilibrium were computed for each locus using FSTAT 2.9.3 (Goudet 1995) and presented as $F_{\text {IS }}$ (calculated as smallF; Weir and Cockerham 1984) with significance levels based on 140,000 permutations. In all FSTAT analyses, the number of permutations was automatically determined based on either the number of loci multiplied by the number of populations in the experimental design (e.g., for $F_{\mathrm{IS}}$ ), or calculated for all loci together as the number of possible pairwise comparisons (e.g., for pairwise $F_{\text {ST }}$ ). Micro-Checker 2.2.3 (van Oosterhout et al. 2004) was used to check for microsatellite null alleles and scoring errors. Linkage disequilibrium values were calculated using FSTAT with $P$ values based on 450,000 permutations. Number of alleles per population, corrected for sample size and expressed as allelic richness $\left(A_{\mathrm{r}}\right)$, were also calculated using FSTAT, whereas observed, expected and unbiased heterozygosities (corrected for sample size) and private alleles were calculated using GenAlEx. Bottleneck 1.2.02 (Cornuet and Luikart 1996) was used to check for recent bottleneck events using a two-phased mutation model with $12 \%$ variance, $95 \%$ stepwise mutation model and 10,000 iterations, after which a one-tailed Wilcoxon test of heterozygote excess and a mode shift test were performed (Peery et al. 2012). Lastly, a one-sided comparison $(9,999$ permutations) of the allelic richness $A_{\mathrm{r}}$ was performed using FSTAT to find out whether this parameter was significantly different between the EAC, NMC and SMC regions of the WIO.

\section{Population structure within the WIO and Red Sea}

To investigate differentiation amongst populations, pairwise $F_{\mathrm{ST}}$ values were estimated using the method of Weir and Cockerham (1984), $(\theta)$ implemented in FSTAT and tested for significance with 91,000 permutations. Statistical significance for all pairwise tests was adjusted for multiple comparisons using a Bonferroni correction. Pairwise $F_{\text {ST }}$ values were used in a Mantel test of isolationby-distance with 9,999 permutations in GenAlEx. The pairwise geographical distance was measured as the shortest path possible by water between two sample sites in Google Earth Pro (www.google.com/earth). GenAlEx was also used to calculate pairwise $D_{\mathrm{EST}}$ (Jost 2008) as an additional measure of differentiation and significance was tested with 9,999 permutations. SPAGeDI (Hardy and Vekemans 2002) was used to test if the assumption of stepwise mutations was met, in which case $R_{\mathrm{ST}}$ would reflect population differentiation better than $F_{\mathrm{ST}}$. Additionally, the relative contribution of mutation versus migration to population differentiation over distance intervals was investigated using 20,000 permutations. A significant $R_{\mathrm{ST}}$ would emphasise the role of mutation relative to migration rate in the differentiation of distant populations.

The software STRUCTURE 2.3.4 (Pritchard et al. 2000), which is a model-based clustering method, was run without prior population information and under the admixture model to determine the most likely number of genetic clusters (K). STRUCTURE was run for $K=1-14$, using 10 runs with a burn-in of 100,000 generations followed by $1,000,000$ additional cycles. Additionally, two separate STRUCTURE analyses were run for the WIO $(K=1-12)$, and for the African mainland $(K=1-8)$, using the same settings. HARVESTER 0.6.94 (Earl and Vonholdt 2012) was used to visualise and analyse the STRUCTURE output by plotting the log probability $\mathrm{L}(\mathrm{K})$ and $\Delta K$ (Evanno et al. 2005).

Patterns of differentiation were also explored using a Discriminant Analysis of Principal Components (DAPC) implemented in the Adegenet package (Jombart 2008) implemented in R (https://www.r-project.org/). The DAPC was run for the whole data set, as well as separately for the WIO, and for the African mainland. The most likely number of clusters (K) was determined based on the lowest value of the Bayesian information criterion (using the function find. clusters). The correct number of principal components to be retained in the analyses was then confirmed by crossvalidation (using the function Xval.dapc).

\section{Haploweb analysis using ITS2}

To investigate the possible occurrence of cryptic species among our samples, a haplotype web (haploweb) of nuclear ITS2 sequences was constructed as described in Flot et al. (2010), using the coral-specific primers ITSc25 and R28S1 to amplify ITS2 for six to eight individuals from each sample site (details of the PCR conditions are provided in Appendix S3). The PCR products were sequenced in both forward and reverse directions using the same primers as for amplification. The resulting sequences were assembled and cleaned manually in Sequencher 4.14 (Gene Codes Corporation, Ann Arbor, MI, USA). The haplotypes of length-variant heterozygotes were determined computationally by combining the information from the forward and reverse chromatograms (Flot et al. 2006) using the online programme Champuru (Flot 2007). The haplotypes of the other heterozygotes were resolved using the programmes SeqPHASE (Flot 2010) and PHASE 2.1 (Stephens and Scheet 2005; Stephens et al. 2001), taking advantage of 
the known phased previously obtained for length-variant heterozygotes. Finally, the haploweb itself was generated using the online programme HaplowebMaker (https:// eeg-ebe.github.io/HaplowebMaker; Spöri and Flot 2020).

\section{Results}

\section{Genotypic diversity}

Of the 356 sampled colonies, 341 were found to harbour unique multilocus genotypes. PIs were low for all sites (PI $<0.01$, except in Zanzibar PI $=0.014)$ and therefore adequate for population studies (Waits et al. 2001). Within the sample sites, nine pairs of identical multilocus genotypes were found: one pair at the sample site Shi'b Al Bayda, two pairs at Kisite, three pairs at Zanzibar, two pairs at Nosy Be, and one pair at Toliara. Additionally, seven identical multilocus genotypes were found in sample site Toliara. As these individuals were most likely the result of the fragmentation of a colony, only one individual from each multilocus genotype was kept in ensuing analyses.

\section{Genetic diversity}

The ten microsatellite markers amplified for all 14 sample sites except for locus Sh2-005 in sample site Ramena. Therefore, all analyses were performed both with and without locus Sh2-005. Four sample sites (Misali, Vamizi,
Pemba and Nosy Be) showed positive $F_{\text {IS }}$ values and significant departures from Hardy-Weinberg equilibrium, indicating heterozygote deficits (Table 1). Further analysis with Micro-Checker found that two sample sites, Mikindani (locus Sh3-009) and Vamizi (locus Sh2-005), possibly had null alleles (Appendix S4). Null alleles were only suspected for two loci, each for a single site, therefore all loci were included in subsequent data analyses. Two loci (Sh3-009 and Sh4.28) were found to be polymorphic for all sample sites, whereas the other loci were monomorphic for at least one sample site (Appendix S5).

The allelic richness $\left(A_{\mathrm{r}}\right)$ ranged between 1.5 and 2.4, the observed heterozygosity $\left(H_{\mathrm{O}}\right)$ between 0.166 and 0.367 and the unbiased expected heterozygosity $\left(\mathrm{u} H_{\mathrm{E}}\right)$ between 0.198 and 0.409 (Table 1). Private alleles were found more frequently in the southern sites, with a maximum of seven in Nacala. A separate analysis after grouping the populations from the Red Sea, Madagascar and of the other sample sites revealed 2, 12 and 18 private alleles, respectively. No significant linkage disequilibrium was detected. None of the populations showed evidence of a recent bottleneck and all sample sites showed normal L-shaped distribution of allele frequencies. The one-sided comparisons of $A_{\mathrm{r}}$ within the WIO showed significantly higher $A_{\mathrm{r}}$ when comparing sites within the EAC and NMC, with $A_{\mathrm{r}}=1.7$ and $A_{\mathrm{r}}=2.0$, respectively (EAC $<$ NMC, $P<0.05$ ), and higher $A_{\mathrm{r}}$ in the SMC $\left(A_{\mathrm{r}}=2.3\right.$, SMC $>$ EAC, $P<0.05$; SMC $>$ NMC, $P<$ 0.05 ). However, since only two sample sites (Salary and Toliara) were analysed in SMC, these results are not
Table 1 Genetic diversity in Seriatopora hystrix from the Western Indian Ocean and the Red Sea.

\begin{tabular}{llllllll}
\hline Sample site & Site code & $n$ & $H_{\mathrm{O}}$ & $\mathrm{u} H_{\mathrm{E}}$ & $A_{\mathrm{r}}$ & $F_{\mathrm{IS}}$ & $P V A$ \\
\hline Ras Masturah & $\mathrm{RM}$ & 14 & $0.202 \pm 0.081$ & $0.214 \pm 0.084$ & 1.742 & 0.058 & 0 \\
Shi'b Al Bayda & $\mathrm{SB}$ & 27 & $0.246 \pm 0.077$ & $0.248 \pm 0.083$ & 1.803 & 0.006 & 1 \\
Kisite & $\mathrm{Ki}$ & 30 & $0.217 \pm 0.086$ & $0.261 \pm 0.088$ & 1.721 & 0.170 & 0 \\
Misali & $\mathrm{Mi}$ & 44 & $0.232 \pm 0.085$ & $0.296 \pm 0.096$ & 1.856 & $0.217^{*}$ & 0 \\
Zanzibar & $\mathrm{Za}$ & 25 & $0.166 \pm 0.076$ & $0.198 \pm 0.074$ & 1.504 & 0.163 & 0 \\
Mafia & $\mathrm{Mf}$ & 27 & $0.309 \pm 0.073$ & $0.351 \pm 0.079$ & 1.950 & 0.122 & 0 \\
Mikindani & $\mathrm{Mk}$ & 19 & $0.252 \pm 0.063$ & $0.318 \pm 0.091$ & 1.931 & 0.210 & 0 \\
Vamizi & $\mathrm{Va}$ & 21 & $0.324 \pm 0.070$ & $0.406 \pm 0.092$ & 2.354 & $0.206^{*}$ & 1 \\
Pemba & $\mathrm{Pe}$ & 16 & $0.213 \pm 0.084$ & $0.295 \pm 0.078$ & 1.848 & $0.285^{*}$ & 0 \\
Nacala & $\mathrm{Na}$ & 20 & $0.255 \pm 0.117$ & $0.253 \pm 0.116$ & 1.906 & -0.008 & 7 \\
Nosy Be & $\mathrm{Nb}$ & 27 & $0.183 \pm 0.068$ & $0.249 \pm 0.085$ & 1.837 & $0.266^{*}$ & 2 \\
Ramena & $\mathrm{Ra}$ & 22 & $0.250 \pm 0.072$ & $0.266 \pm 0.069$ & 1.840 & 0.061 & 2 \\
Salary & $\mathrm{Sa}$ & 33 & $0.361 \pm 0.079$ & $0.392 \pm 0.079$ & 2.224 & 0.081 & 1 \\
Toliara & $\mathrm{To}$ & 16 & $0.367 \pm 0.101$ & $0.409 \pm 0.069$ & 2.314 & 0.105 & 4 \\
\hline For geograp
\end{tabular}

For geographical location of the sample sites see Fig. 1 and Appendix S1.

$n$ sample size, $A_{\mathrm{r}}$ allelic richness calculated without locus Sh2-005, $H_{\mathrm{O}}$ observed heterozygosity $( \pm \mathrm{SD}), \mathrm{u} H_{\mathrm{E}}$ unbiased expected heterozygosity $( \pm \mathrm{SD}), F_{\mathrm{IS}}$ departure from Hardy-Weinberg equilibrium, positive values indicate a deficit of heterozygotes, $P V A$ number of private alleles.

${ }^{*} P<0.001$, significant departure from zero is based on 140,000 randomisations, $P$ values have been corrected for multiple tests. 


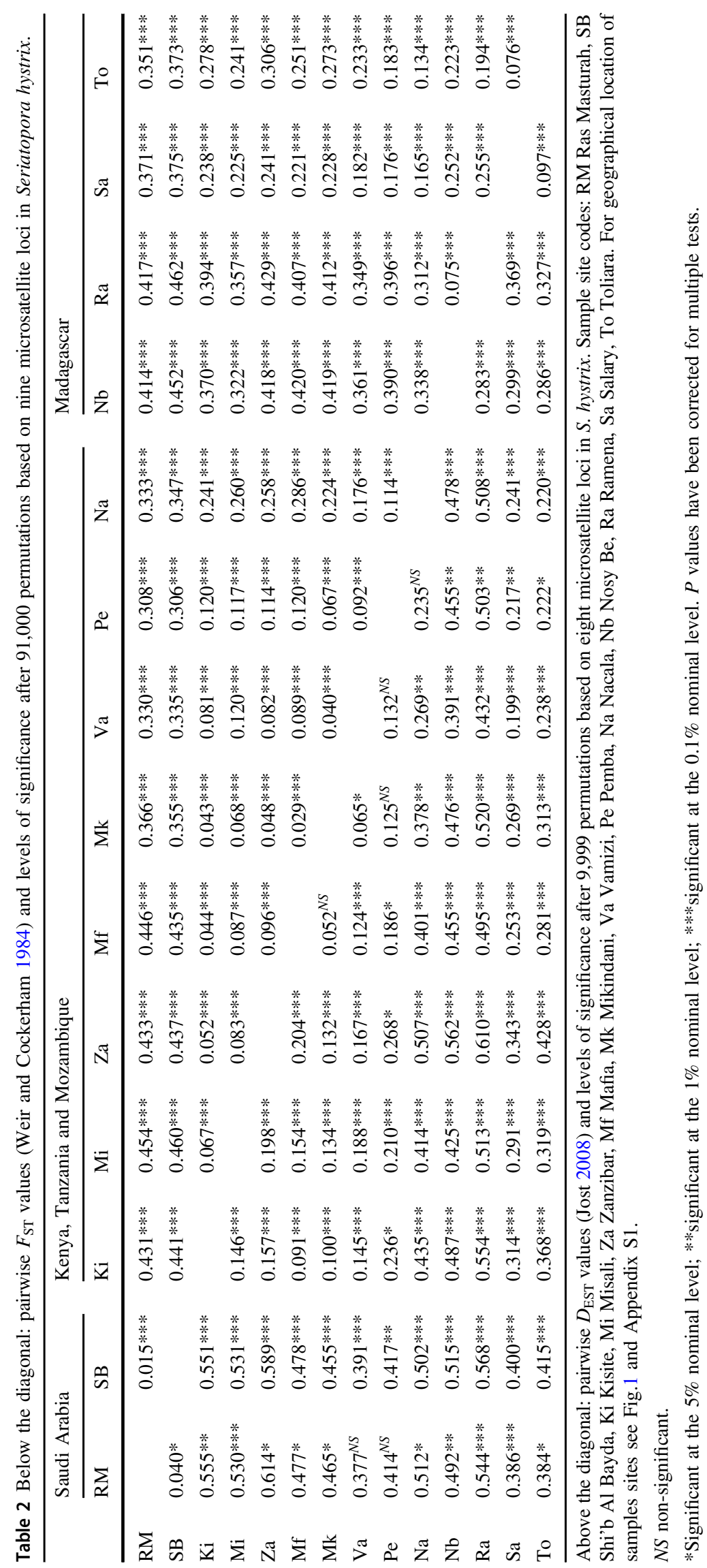




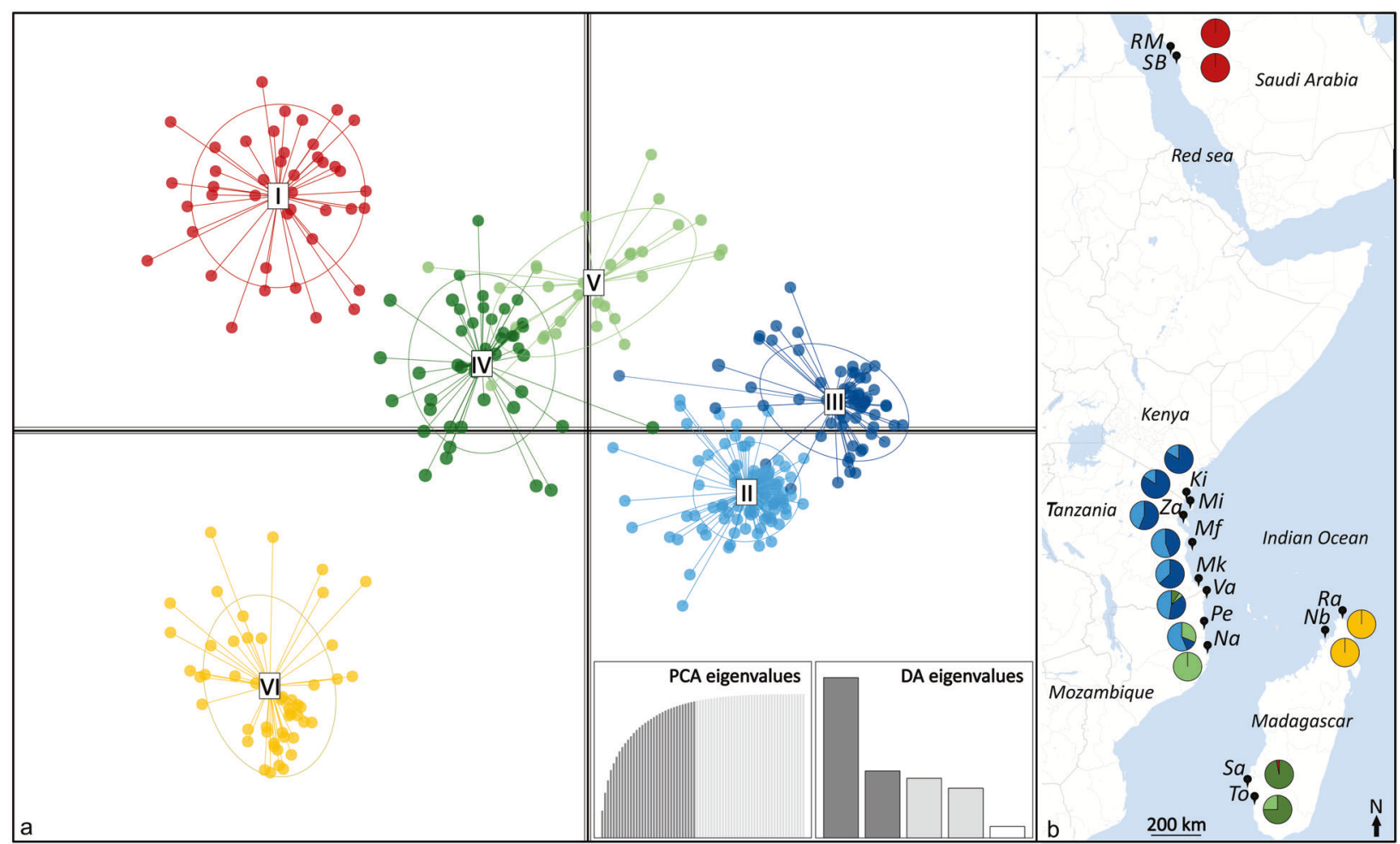

Fig. 2 Discriminant Analysis of Principal Components (DAPC) in Seriatopora hystrix based on ten microsatellite loci. (in Adegenet; Jombart (2008), 33 principal components retained) a DAPC plot: the dots represent individuals, while the different colours represent six clusters identified by Bayesian analyses: cluster I all individuals in the Red Sea; clusters II and III all individuals along the coast of Kenya and Tanzania and some individuals in the north of Mozambique; clusters IV and V individuals from north of Mozambique and south of

included in the discussion. When considering the NMC without Madagascar, the NMC region still had a higher $A_{\mathrm{r}}$ $\left(A_{\mathrm{r}}=2.0\right.$, EAC $<$ NMC mainland, $\left.P<0.05\right)$.

\section{Population structure}

The sample sites were highly differentiated according to pairwise $F_{\mathrm{ST}}$ values, with significant differentiation found in $94 \%$ of the pairwise population comparisons (Table 2). The highest genetic differentiation was found for the Red Sea sites Ras Masturah (0.377-0.614) and Shi'b Al Bayda (0.391-0.589) versus all other sites. Two comparisons were not significant, Ras Masturah versus Pemba and Ras Masturah versus Vamizi, which can probably be explained by smaller sample sizes in these sites. Within the WIO, a strong differentiation between the East African mainland and sites in Madagascar was observed, especially for Nosy Be (0.283-0.562) and Ramena (0.327-0.610) versus all other sites, as well as for Salary $(0.097-0.369)$ and Toliara $(0.097-0.428)$ in south-west Madagascar. At the East African mainland, differentiation was lower in Kenya and northern
Madagascar; cluster VI all individuals from the north of Madagascar. b The pie charts show the distribution of the six genetic clusters identified by DAPC at the sample sites in the Red Sea and Western Indian Ocean. Sample site codes: RM Ras Masturah, SB Shi'b Al Bayda, Ki Kisite, Mi Misali, Za Zanzibar, Mf Mafia, Mk Mikindani, Va Vamizi, Pe Pemba, Na Nacala, Nb Nosy Be, Ra Ramena, Sa Salary, To Toliara.

Tanzania, but higher in southern Tanzania and in Mozambique, with Nacala showing high differentiation compared to all other sites, except to adjacent reefs (Pemba and Vamizi) and sites in south-west Madagascar (Salary and Toliara). The Mantel test showed a significant correlation between population differentiation and geographical distance for all sites in the WIO $\left(R^{2}=0.32, P\right.$ $=0.02$; Appendix S6) as well as for sample sites from the region comprising Kenya, Tanzania and northern Mozambique $\left(R^{2}=0.40, P=0.0001\right.$; Appendix S6).

$D_{\mathrm{EST}}$ was congruent with $F_{\mathrm{ST}}$ values (Table 2), indicating that $F_{\mathrm{ST}}$ did not underestimate the level and pattern of differentiation. Although similar gradients were observed for both measures, consistently lower values of $D_{\text {EST }}$ were found for the East African mainland sites, suggesting a higher influence of migration over mutation rates. The contribution of stepwise mutations $\left(R_{\mathrm{ST}}>F_{\mathrm{ST}}\right)$ was tested with a one-sided permutation test, but only with the five most polymorphic loci (Sh3-004, Sh2-005, Sh4-001, Sh3009 and Sh4.28), as the permutation test was shown to be unreliable for loci with lower polymorphism (Hardy et al. 2003). Significant $(P<0.05)$ contributions of stepwise 
mutations in allele size were detected for four loci. However, analyses of distance intervals showed that significant values were only found for distances beyond $738 \mathrm{~km}$ (loci Sh3-004, Sh4-001, Sh-009 and Sh4.28; Appendix S7). Additional testing of two groups, WIO $(<4000 \mathrm{~km})$ and Red Sea $(>4000 \mathrm{~km})$, revealed significant $(P<0.05)$ contributions of stepwise mutations for two loci (Sh3-004 and Sh4001). The Bayesian clustering implemented in STRUCTURE showed both a plateau for the log probability and an optimum $\Delta K$ for $K=5$, the most likely number of genetic clusters for all sample sites (Appendix S8 and Fig. 1a, b). Based on the proportion of each genetic cluster within each sample site, four groups of sample sites were identified: (1) Saudi Arabia (Ras Masturah, Shi'b Al Bayda); (2) sites in Kenya, Tanzania and northern Mozambique (Kisite, Misali, Zanzibar, Mafia, Mikindani, Vamizi, Pemba) forming a mixed group of two genetic clusters, although based on cluster distribution a shallow structure of northern sites (Kisite, Misali, Zanzibar) and southern sites (Mafia, Mikindani, Vamizi, Pemba) was observed; (3) one site in northern Mozambique (Nacala) and sites in south-west Madagascar (Salary, Toliara); and (4) northern Madagascar (Nosy Be, Ramena). These patterns were confirmed comparing different $K$ values ( $K=1-14$, Appendix S8) as well as with separate STRUCTURE analyses for the WIO and for the African mainland (data not shown).

The DAPC revealed six clustes (Fig. 2, cluster I-VI) of S. hystrix, corresponding to the five clusters identified by STRUCTURE plus an additional cluster shared between northern Mozambique and south-west Madagascar. These clusters could be divided into four groups: (1) Cluster I in Saudi Arabia (Ras Masturah, Shi'b Al Bayda); (2) Clusters II and III in Kenya, Tanzania and some individuals from northern Mozambique (Kisite, Misali, Zanzibar, Mafia, Mikindani, Vamizi, Pemba); transitioning to group (3) formed by Cluster IV and Cluster V in northern Mozambique and south-west Madagascar (Vamizi, Pemba, Nacala, Salary, Toliara); and a separate group (4) formed by Cluster VI in northern Madagascar (Nosy Be, Ramena).

\section{Haploweb analysis using ITS2}

The ITS2 marker was successfully sequenced for 77 out of 85 samples of $S$. hystrix. There were 30 homozygous individuals and 47 heterozygous individuals, hence a total of 124 sequences corresponding to 24 haplotypes 566-572 bp long (Fig. 1c). In haplowebs, groups of individuals sharing a pool of alleles interconnected by allele sharing in heterozygotes are called fields for recombination (FFRs, following the terminology of Doyle 1995), each of which corresponds to one putative species (Flot et al. 2010). This analysis revealed two distinct FFRs: FFR I comprised all individuals collected in the Red Sea, whereas FFR II comprised all individuals collected in the WIO. Within FFR I, four haplotypes were found in ten individuals from two locations in the Red Sea. Within FFR II, 20 haplotypes were found in 67 individuals from 12 locations in the WIO, of which the most prevalent haplotype was found in 40 individuals from 11 different locations. Because distinct FFRs suggest the occurrence of two different species, all analyses described above were also performed without the sample sites in the Red Sea, which provided similar results and interpretation (data not shown).

\section{Discussion}

This study investigated the large-scale genetic patterns of the brooding scleractinian coral S. hystrix within the Red Sea and WIO using microsatellite markers and the nuclear marker ITS2. Since $S$. hystrix is a brooding coral, higher genetic subdivision was expected than in other widespread species with a broadcast spawning reproduction strategy. This was the first coral population genetic study to include both the Red Sea and the WIO, and the first to include a substantial part of the East African coastline, as well as Madagascar.

\section{Isolation of the Red Sea}

The Saudi Arabian sample sites in the Red Sea are strongly differentiated from the sites in East Africa based on microsatellite data and the ITS2 marker. This confirms the a priori hypothesis of a strong genetic barrier between the Red Sea and the WIO, which may be explained either by historical and contemporary barriers or by interspecific boundaries. Sample sites in the Red Sea and the WIO belong to two different marine provinces (Spalding et al. 2007): the Red Sea/Gulf of Aden and the WIO. The Red Sea is a marine biodiversity hotspot with a high percentage of endemic species $5.5 \%$ of scleractinian corals species, $10 \%$ of crustaceans, $8.1 \%$ of echinoderms and $14.1 \%$ of fish; DiBattista et al. 2016). Strong isolation of Red Sea populations from the WIO has been previously reported for corals (Pinzón et al. 2013), fishes (discussed, e.g., in Froukh and Kochzius 2008; DiBattista et al. 2013, 2016), arthropods (e.g., Iacchei et al. 2016), echinoderms (Vogler et al. 2008), molluscs (e.g., Hui et al. 2016) and sponges (Wörheide et al. 2008), although some studies found no dispersal barriers for some fish species (DiBattista et al. 2013; Kochzius and Blohm 2005). The Red Sea was formed $\sim 24$ million years ago and, although currently connected to the Indian Ocean through the shallow Bab-el-Mandeb Strait, it experienced historic isolation from the Indian Ocean during lower sea levels in glacial cycles, causing periods of extreme desiccation and hypersalinity (Siddall et al. 2003). 
Whether corals survived these conditions in refugia or recolonised the Red Sea from the Gulf of Aden remains under discussion (DiBattista et al. 2013). In addition to historical barriers, corals in the Red Sea experience dispersal barriers such as eddies in the central Red Sea region as well as turbidity in the southern Red Sea (Roberts et al. 1992). Strong isolation through historical and contemporary barriers could have resulted in a speciation and a subsequent interspecies boundary. In the ITS2 haploweb individuals from the Red Sea and WIO indeed belong to two distinct FFRs, suggesting that they correspond to two different species using the criterion of mutual allelic exclusivity (Flot et al. 2010). However, our sampling design did not include intermediate reefs and this preliminary result is based on a single marker (ITS2), for which the occurrence of paralogs could not be ruled out in this study. The putative species boundary between our WIO and Red Sea samples will need to be verified using morphological and novel multilocus molecular approaches based on RADseq and/or ultraconserved elements and exons (Schmidt-Roach et al. 2014; Erickson et al. 2020; Arrigoni et al. 2020) before a definitive conclusion can be reached.

\section{Strong differentiation of northern Madagascar}

While the ITS2 analyses ruled out the occurrence of cryptic species in northern Madagascar (Nosy Be and Ramena), a strong differentiation from all other sites in the WIO was detected using microsatellite markers, indicating a possible contemporary barrier for larval dispersal. Oceanographic conditions in the NMC could play an important role in isolating these coral populations, specifically the cyclonic eddies that are generated and reside in front of the northwest coast of Madagascar (Collins et al. 2014). Different dispersal models support this isolation, showing that coral larvae released from north-west Madagascar are mostly selfrecruiting, which is especially true for coral species with a short PLD such as S. hystrix (Crochelet et al. 2016; Gamoyo et al. 2019).

\section{Contemporary genetic connectivity between northern Mozambique and south-west Madagascar}

The individual-based cluster analyses, in which individuals from northern Mozambique are clustered with individuals from the south of Madagascar, confirm a degree of connectivity between northern Mozambique (NMC: Nacala) and south-west Madagascar (SMC: Salary and Toliara). Larval dispersal is likely under influence of anticyclonic eddies, generated in the Comoros Basin, after which they proceed southward into the Mozambique Channel. Potential connectivity between northern Mozambique and south-west
Madagascar was demonstrated in drifter experiments (Ramanantsoa et al. 2018). These results are also partly supported by a larval dispersal modelling study (Gamoyo et al. 2019), in which strong southward dispersal and subsequent transport in the Mozambique Channel eddies were found for larvae released from sites south of Pemba (Mozambique), although this study did not include sites south of Nacala. However, successful exchange of coral larvae is unlikely to be frequent, considering the high differentiation found here between northern Mozambique and south-west Madagascar. This is congruent with the results of a larvae dispersal model in the WIO by Crochelet et al. (2016), in which these sites were found to belong to two separate clusters with a lower potential exchange of larvae. Here, no S. hystrix colonies were found in Mozambique south of Nacala (for which the sampling campaign included Vilanculos, Pembane, Tofo, Xai-Xai, Inhaca and Ponta do Ouro), although S. hystrix was predicted to occur there (https://www.coralsoftheworld.com, accessed 13 Oct 2019). Indeed, recent expeditions recorded $S$. hystrix in Ilha Caldeira and Bazaruto (Vilanculos) in the Mozambique Channel. However, only Seriatopora caliendrum was recorded for sites further south along the coast (Schleyer and Celliers 2000, 2005). Further sampling and verification of records of $S$. hystrix south of Nacala will be required before definite conclusions on the regional substructure along the whole coastline of Mozambique can be drawn.

\section{Genetic structure along the East African Coast (EAC)}

Substantial subdivision was also found amongst coral reefs along the EAC: pairwise differentiation was high, although lower than amongst other sites in the WIO (except Nacala, as discussed above). However, when comparing the results of our different analyses, no definite genetic breaks were found, similarly to what was previously reported for a coral with a mixed reproduction strategy Pocillopora damicornis in Kenya (Souter et al. 2009), for the broadcast spawner Platygyra daedalea in Kenya (Souter and Grahn 2008), as well as for the broadcast spawner Acropora tenuis in Kenya and Tanzania (van der Ven et al. 2016). Although the overall level of genetic differentiation between sites in these studies was substantially lower than in the case of $S$. hystrix and no isolation-by-distance was found. This could be explained by differences in life histories of these corals, such as reproductive strategies associated with longer PLD and subsequent increased connectivity among surrounding reefs (Crochelet et al. 2016). Genetic connectivity without a clear genetic break was also found in molluscs (Ratsimbazafy and Kochzius 2018; Nehemia et al. 2019), arthropods (Rumisha et al. 2017) and fishes (Huyghe and Kochzius 2018). S. hystrix has a short PLD, resulting in high levels of self-recruitment with 
the majority of larvae settling within $100 \mathrm{~m}$ of their mother colony in north-west Australia (Underwood et al. 2007), although longer distance dispersal can occur (van Oppen et al. 2008). Comparable levels of differentiation were found for $S$. hystrix on the Great Barrier Reef and in northern Western Australia (mean $F_{\mathrm{ST}}=0.20 \sim 500 \mathrm{~km}$, van Oppen et al. 2008), including isolation-by-distance (overall $F_{\mathrm{ST}}=$ $0.198 \sim 505 \mathrm{~km}$, Underwood et al. 2009). Low differentiation was found in the Red Sea over a distance of $610 \mathrm{~km},\left(F_{\mathrm{ST}}=\right.$ 0.089 ; Maier et al. 2005), but the lower mean $F_{\mathrm{ST}}$ value can be explained by the proximity of most of the sample sites, e.g., $\sim 0.15 \mathrm{~km}$ and the use of only three microsatellite loci. Based on the prevalence of clusters in the Bayesian analyses, there is an indication for a gradient in the WIO, with one cluster more dominant in the north (EAC: Kisite, Misali and Zanzibar) and one or two clusters more dominant in the south (NMC: Mafia, Mikindani, Vamizi and Pemba; Fig. 1a, b), although Mikindani shows more resemblance to the northern sites in the DAPC analysis (Fig. 2b). This distinction between sites may be explained by different oceanographic conditions. The northern sites are under year-round influence of the EACC, while the southern sites are part of the NMC with influence of the Mozambique Channel eddies, the bifurcation of the SEC in front of the African continent and the transition of the SEC into the EACC (Lutjeharms and Bornman 2010; Schott and McCreary 2001). Since the southern sites are part of the NMC region, they present a similar genetic signature caused by an exchange of larvae between northern Mozambique and Mikindani, and further transport of larvae from Mikindani to Mafia, with high genetic connectivity between Mikindani and Mafia supported by lower pairwise $F_{\mathrm{ST}}$ values. This pattern was also suggested for $A$. tenuis (van der Ven et al. 2016) and is supported by the strong resemblance in coral species diversity between these sites (Obura 2012). Although no bottleneck was detected, we cannot exclude false negatives caused by small sample sizes and subsequent limited statistical power in this data set (Peery et al. 2012). The aforementioned gradient may therefore be the result of severe historic bleaching events that have impacted the northern and southern sample sites differently. Pocilloporids exhibit a low tolerance to elevated sea surface temperatures (Marshall and Baird 2000) and suffered substantial losses during the 1998 El Niño in the WIO (Wilkinson 2002), with up to $100 \%$ mortality on some reefs in Kenya (McClanahan et al. 2001). However, reefs further south within the NMC seem to have evaded environmental conditions triggering bleaching events and still support bleaching-susceptible coral taxa (McClanahan et al. 2007a, 2014). Subsequent recolonisation of northern sites may have come from various source populations not sampled in this study, such as reefs further north and deeper refugia or mesophotic reefs, which can potentially contribute larvae to shallower reefs (Prasetia et al. 2017; van Oppen et al. 2011).

\section{Genetic diversity in the Northern Mozambique Channel}

Allelic richness was significantly higher at the sites in the NMC compared to sites further north, both when including mainland and Madagascar sites and for mainland sites alone. These results are consistent with the higher coral cover and diversity found in the NMC, which can be explained by current patterns (such as the inflow of the SEC transporting larvae) combined with the high connectivity caused by mixing in the NMC eddies, and lower environmental stress than north of the NMC (McClanahan et al. 2014; Obura 2012). These complex oceanographic patterns also influence coral reef communities, because of the differences in sensitivity to temperature anomalies between coral species: the EACC along the coast of Tanzania and Kenya shows more frequent temperature fluctuations, while the SEC has a stabilising influence on the temperature in the region (McClanahan et al. 2011, 2007b, 2014). This could explain the higher abundance of temperature-sensitive taxa, such as acroporids and pocilloporids in the NMC, although variable levels of bleaching did occur in this region, for instance in Mayotte (Eriksson et al. 2012; Marshall and Baird 2000; McClanahan et al. 2014; Obura 2012; Obura et al. 2018).

In conclusion, the brooding stony coral $S$. hystrix shows a limited dispersal capacity and a high differentiation both at a large scale between the Red Sea and the WIO $(>6000 \mathrm{~km})$, and at smaller scale for sites along the coast of Tanzania and Kenya (Kisite and Misali; $<65 \mathrm{~km}$ ).

Red Sea populations of $S$. hystrix could belong to a different species than the populations in the WIO, which should form the basis for further integrated taxonomy studies. Within the WIO, three groups can be distinguished inhabiting (1) the north of Madagascar, (2) the south-west of Madagascar together with one site in northern Mozambique (Nacala) and (3) all other sites along the coast of northern Mozambique, Tanzania and Kenya. These patterns of contemporary dispersal barriers can be explained by the short PLD of $S$. hystrix and by oceanographic conditions, such as eddies in the Mozambique Channel causing larval retention in northern Madagascar, while the prevailing northbound EACC likely facilitates higher connectivity along the northern EAC. The strong genetic population structure in this study is congruent with findings for the same species from other biogeographic regions such as Australia (van Oppen et al. 2008; Underwood et al. 2009) and Japan (Nakajima et al. 2017), as well as for other brooding corals with a similarly short PLD. When comparing brooding corals with broadcast spawning corals with longer PLD, the importance of the reproduction strategy on connectivity is shown, with substantially lower levels of differentiation found in the broadcast spawning coral in the same region, e.g., $A$. tenuis (van der Ven et al. 2016), or other biogeographic regions, e.g., Acropora digitifera in Japan (Nakajima et al. 
2010). These insights into the population structure of corals with different life histories can help to understand which spatial scales conservation initiatives should consider. For instance, this study confirmed assumed connectivity within the EAC for S. hystrix. However, this study also showed that the NMC region is in fact split by contemporary dispersal barriers, probably caused by the short PLD of $S$. hystrix, with on one side northern Madagascar isolated by local cyclonic eddies and on the other side Mozambique and Tanzania influenced by southward moving anticyclonic eddies in the channel. The NMC is considered a priority region for conservation and management efforts, as this region is high in coral cover and species richness, probably caused by historical high connectivity and low or geographically variable levels of environmental stress (McClanahan et al. 2007a, 2014; Obura 2012). In a biophysical modelling study, Crochelet et al. (2016) appointed several sites in this region that are particularly essential for the connectivity of larvae, and Geyser Bank and Cosmoledo were suggested as priority sites for MPAs within the Mozambique Channel. Genetic connectivity studies, and the dispersal barriers described, provide guidance on how to prioritise conservation efforts for coral reefs in the future. However, substantial differences in spatial scales can be expected, even within functional and taxonomically similar assemblages, such as corals. Therefore, there may not be a "one-size-fits-all" solution for coral reef conservation, but rather a compromise, which should consider a variety of marine life with diverse life history characteristics.

\section{Data availability}

Microsatellite genotypes and ITS2 DNA sequence data available in the Dryad Digital Repository: https://doi.org/ 10.5061/dryad.gtht76hjz.

Acknowledgements We would like to thank the funding agencies that supported our work: Fonds Wetenschappelijk Onderzoek Vlaanderen (FWO) for funding the project, Connectivity of Coral Reefs and Mangroves in the Western Indian Ocean (COCOMA-WIO; grant 1501612N); the Vrije Universiteit Brussel (VUB) (OZR2068BOF) and the Fonds de la Recherche Scientifique-FNRS (research grant J.0272.17 to JFF) for additional support; the Vlaamse Interuniversitaire-Raad Universitaire Ontwikkelingssamenwerking (VLIR-UOS), the doctoral school (VUB), and the Leopold III Fund for nature research and conservation for providing travel grants to RMV; European Union Erasmus Mundus Programme CARIBU, VLIR-UOS and King Abdullah University for Science and Technology (Saudi Arabia) for providing travel grants to MK; T. Sierens (VUB) for assistance during laboratory work; H.A. Ratsimbazafy (VUB and Université de Tuléar, Madagascar), L. Otwoma (VUB and Kenya Marine and Fisheries Research Institute, Kenya) and B. Cowburn (University of Oxford, UK) for collecting samples; D. De Ryck (VUB), F. Huyghe (VUB), M.S. Mohammed (State University of Zanzibar, Tanzania), V. Muhala (Eduardo Mondlane University, Mozambique) and M. Berumen (King Abdullah University for Science and Technology, Saudi Arabia) for assistance during fieldwork; M. Sheikh (State University of Zanzibar, Tanzania) for logistical support; the competent authorities in Kenya, Madagascar, Mozambique, Saudi Arabia and Tanzania for permits; L. Triest (VUB) for help with analyses and interpretation of the results; B. Vanschoenwinkel (VUB), N. van Hoytema (Centre for Environment, Fisheries and Aquaculture Science (Cefas), UK) and N. Hicks (University of Essex, UK) for proofreading the paper and making critical suggestions to improve it. Lastly, we would like to thank the three anonymous reviewers for their constructive feedback and improvements of the paper.

\section{Compliance with ethical standards}

Conflict of interest The authors declare that they have no conflict of interest.

Publisher's note Springer Nature remains neutral with regard to jurisdictional claims in published maps and institutional affiliations.

\section{References}

Adjeroud M, Guerecheau A, Vidal-Dupiol J, Flot JF, Arnaud-Haond S, Bonhomme F (2014) Genetic diversity, clonality and connectivity in the scleractinian coral Pocillopora damicornis: a multi-scale analysis in an insular, fragmented reef system. Mar Biol 161(3):531-541

Arrigoni R, Berumen ML, Mariappan KG, Beck PSA, Hulver AM, Montano $\mathrm{S}$ et al. (2020) Towards a rigorous species delimitation framework for scleractinian corals based on RAD sequencing: the case study of Leptastrea from the Indo-Pacific. Coral Reefs 39:1001-1025

Baird AH (2001) The ecology of coral larvae: settlement patterns, habitat selection and the length of the larval phase. Doctoral dissertation, James Cook University, Townsville

Collins C, Hermes JC, Reason CJC (2014) Mesoscale activity in the Comoros Basin from satellite altimetry and a high-resolution ocean circulation model. J Geophys Res Oceans 119:4745-4760

Cornuet JM, Luikart G (1996) Description and power analysis of two tests for detecting recent population bottlenecks from allele frequency data. Genetics 144(4):2001-2014

Costanza R, de Groot R, Sutton P, van der Ploeg S, Anderson SJ, Kubiszewski I et al. (2014) Changes in the global value of ecosystem services. Glob Environ Chang 26:152-158

Cowen R, Sponaugle S (2009) Larval dispersal and marine population connectivity. Ann Rev Mar Sci 1:443-466

Crochelet E, Roberts J, Lagabrielle E, Obura DO, Petit M, Chabanet P (2016) A model-based assessment of reef larvae dispersal in the Western Indian Ocean reveals regional connectivity patterns - potential implications for conservation policies. Reg Stud Mar Sci 7:159-167

Dana JD (1846) United States Exploring Expedition. Vol. VII. Zoophytes. C. Sherman, Philadelphia

Dellicour S, Flot JF (2015) Delimiting species-poor data sets using single molecular markers: a study of barcode gaps, haplowebs and GMYC. Syst Biol 64(6):900-908

Dellicour S, Flot JF (2018) The hitchhiker's guide to single-locus species delimitation. Mol Ecol Resour 18(6):1234-1246

DiBattista JD, Berumen ML, Gaither MR, Rocha LA, Eble JA, Choat JH et al. (2013) After continents divide: comparative phylogeography of reef fishes from the Red Sea and Indian Ocean. J Biogeogr 40(6):1170-1181

DiBattista JD, Roberts MB, Bouwmeester J, Bowen BW, Coker DJ, Lozano-Cortes DF et al. (2016) A review of contemporary patterns of endemism for shallow water reef fauna in the Red Sea. J Biogeogr 43(3):423-439

Doyle JJ (1995) The irrelevance of allele tree topologies for species delimitation, and a non-topological alternative. Syst Bot 20 (4):574 
Earl D, Vonholdt B (2012) STRUCTURE HARVESTER: a website and program for visualizing STRUCTURE output and implementing the Evanno method. Conserv Genet Resour 4 (2):359-361

Erickson KL, Pentico A, Quattrini AMMc, Fadden CS (2020) New approaches to species delimitation and population structure of anthozoans: two case studies of octocorals using ultraconserved elements and exons Mol Ecol Resour https://doi.org/10.1111/ 1755-0998.13241

Eriksson H, Wickel J, Jamon A (2012) Coral bleaching and associated mortality in Mayotte, Western Indian Ocean. West Indian Ocean J Mar Sci 11:113-118

Evanno G, Regnaut S, Goudet J (2005) Detecting the number of clusters of individuals using the software STRUCTURE: a simulation study. Mol Ecol 14(8):2611-2620

Fisher R, O'Leary RA, Low-Choy S, Mengersen K, Knowlton N, Brainard RE et al. (2015) Species richness on coral reefs and the pursuit of convergent global estimates. Curr Biol 25(4):500-505

Flot JF (2007) CHAMPURU 1.0: a computer software for unraveling mixtures of two DNA sequences of unequal lengths. Mol Ecol Notes 7(6):974-977

Flot JF (2010) SeqPHASE: a web tool for interconverting phase input/ output files and fasta sequence alignments. Mol Ecol Resour 10 (1):162-166

Flot JF (2015) Species delimitation's coming of age. Syst Biol 64 (6):897-899

Flot JF, Couloux A, Tillier S (2010) Haplowebs as a graphical tool for delimiting species: a revival of Doyle's "field for recombination" approach and its application to the coral genus Pocillopora in Clipperton. BMC Evol Biol 10:372

Flot JF, Licuanan WY, Nakano Y, Payri C, Cruaud C, Tillier S (2008) Mitochondrial sequences of Seriatopora corals show little agreement with morphology and reveal the duplication of a tRNA gene near the control region. Coral Reefs 27:789-794

Flot JF, Tillier A, Samadi S, Tillier S (2006) Phase determination from direct sequencing of length-variable DNA regions. Mol Ecol Notes 6(3):627-630

Flot JF, Tillier S (2007) The mitochondrial genome of Pocillopora (Cnidaria: Scleractinia) contains two variable regions: the putative D-loop and a novel ORF of unknown function. Gene 401 $(1-2): 80-87$

Fontaneto D, Flot JF, Tang CQ (2015) Guidelines for DNA taxonomy, with a focus on the meiofauna. Mar Biodivers 45(3):433-451

Froukh T, Kochzius M (2008) Species boundaries and evolutionary lineages in the blue green damselfishes Chromis viridis and Chromis atripectoralis (Pomacentridae). J Fish Biol 72(2):451-457

Gamoyo M, Obura DO, Reason CJC (2019) Estimating connectivity through larval dispersal in the Western Indian Ocean. J Geophys Res. 124(8):2446-2459

Goudet J (1995) FSTAT (Version 1.2): a computer program to calculate F-statistics. J Hered 86(6):485-486

Hancke L, Roberts MJ, Ternon JF (2014) Surface drifter trajectories highlight flow pathways in the Mozambique Channel. Deep Sea Res II Top Stud Oceanogr 100:27-37

Hardy OJ, Charbonnel N, Freville H, Heuertz M (2003) Microsatellite allele sizes: a simple test to assess their significance on genetic differentiation. Genetics 163(4):1467-1482

Hardy OJ, Vekemans X (2002) SPAGeDi: a versatile computer program to analyse spatial genetic structure at the individual or population levels. Mol Ecol Notes 2(4):618-620

Harrison PL (2011) Sexual reproduction of scleractinian corals. In: Dubinsky Z, Stambler N (eds) Coral reefs: an ecosystem in transition. Springer, Dordrecht. pp 59-85

Hoegh-Guldberg O, Poloczanska ES, Skirving W, Dove S (2017) Coral reef ecosystems under climate change and ocean acidification. Front Mar Sci 4:158
Hui M, Kraemer WE, Seidel C, Nuryanto A, Joshi A, Kochzius M (2016) Comparative genetic population structure of three endangered giant clams (Cardiidae: Tridacna species) throughout the Indo-West Pacific: implications for divergence, connectivity and conservation. J Molluscan Stud 82:403-414

Huyghe F, Kochzius M (2018) Sea surface currents and geographic isolation shape the genetic population structure of a coral reef fish in the Indian Ocean. PLoS ONE 13(3):e0193825

Iacchei M, Gaither MR, Bowen BW, Toonen RJ (2016) Testing dispersal limits in the sea: range-wide phylogeography of the pronghorn spiny lobster Panulirus penicillatus. J Biogeogr 43 (5): 1032-1044

Isomura N, Nishihira M (2001) Size variation of planulae and its effect on the lifetime of planulae in three pocilloporid corals. Coral Reefs 20:309-315

Jombart T (2008) Adegenet: a R package for the multivariate analysis of genetic markers. J Bioinform 24(11):1403-1405

Jost L (2008) $G_{\mathrm{ST}}$ and its relatives do not measure differentiation. Mol Ecol 17(18):4015-4026

Kochzius M, Blohm D (2005) Genetic population structure of the lionfish Pterois miles (Scorpaenidae, Pteroinae) in the Gulf of Aqaba and northern Red Sea. Gene 347(2):295-301

Lutjeharms J, Bornman $\mathrm{T}$ (2010) The importance of the greater Agulhas Current is increasingly being recognised. S Afr J Sci 106 $(3 / 4): 1-4$

Maier E, Tollrian R, Rinkevich B, Nurnberger B (2005) Isolation by distance in the scleractinian coral Seriatopora hystrix from the Red Sea. Mar Biol 147(5):1109-1120

Marshall P, Baird AH (2000) Bleaching of corals on the Great Barrier Reef: differential susceptibilities among taxa. Coral Reefs 19 (2): $155-163$

McClanahan TR, Ateweberhan M, Graham N, Wilson S, Sebastian C, Guillaume $M$ et al. (2007a) Western Indian Ocean coral communities: bleaching responses and susceptibility to extinction. Mar Ecol Prog Ser 337:1-13

McClanahan TR, Ateweberhan M, Darling ES, Graham NAJ, Muthiga NA (2014) Biogeography and change among regional coral communities across the Western Indian Ocean. PLoS ONE 9(4): e93385

McClanahan TR, Ateweberhan M, Muhando CA, Maina J, Mohammed SM (2007b) Effects of climate and seawater temperature variation on coral bleaching and mortality. Ecol Monogr 77(4):503-525

McClanahan TR, Maina JM, Muthiga NA (2011) Associations between climate stress and coral reef diversity in the western Indian Ocean. Glob Change Biol 17(6):2023-2032

McClanahan TR, Muthiga NA, Mangi S (2001) Coral and algal changes after the 1998 coral bleaching: interaction with reef management and herbivores on Kenyan reefs. Coral Reefs 19 (4):380-391

McLeod E, Anthony KRN, Mumby PJ, Maynard J, Beeden R, Graham NAJ et al. (2019) The future of resilience-based management in coral reef ecosystems. J Environ Manag 233:291-301

Motta H, Pereira MAM, Gonçalves M, Ridgway T, Schleyer MH (2002) Mozambique coral reef management programme. MICOA/CORDIO/ORI/WWF, Maputo, p 31

Nakajima Y, Nishikawa A, Iguchi A, Nagata T, Uyeno D, Sakai K et al. (2017) Elucidating the multiple genetic lineages and population genetic structure of the brooding coral Seriatopora (Scleractinia: Pocilloporidae) in the Ryukyu Archipelago. Coral Reefs 36(2):415-426

Nakajima Y, Nishikawa A, Iguchi A, Sakai K (2010) Gene flow and genetic diversity of a broadcast-spawning coral in northern peripheral populations. PLoS ONE 5:e11149

Nehemia A, Ngendu Y, Kochzius M (2019) Genetic population structure of the mangrove snails Littoraria subvittata and $L$. 
pallescens in the Western Indian Ocean. J Exp Mar Biol Ecol 514-515:27-33

Obura DO (2012) The diversity and biogeography of Western Indian Ocean reef-building corals. PLoS ONE 7(9):e45013

Obura DO, Bandeira SO, Bodin N, Burgener V, Braulik G, Chassot E, et al. (2019) The Northern Mozambique Channel. In: Sheppard W (ed.) World seas: an environmental evaluation. Academic Press, Cambridge. pp 75-99

Obura DO, Bigot L, Benzoni F (2018) Coral responses to a repeat bleaching event in Mayotte in 2010. PeerJ 6:e5305

Obura DO, Gudka M, Rabi FA, Gian SB, Bijoux J, Freed S et al. (2017) Coral reef status report for the Western Indian Ocean. Global Coral Reef Monitoring Network (GCRMN)/International Coral Reef Initiative (ICRI). pp 1-144

Palumbi S (2003) Population genetics, demographic connectivity, and the design of marine reserves. Ecol Appl 13:146-158

Peakall R, Smouse P (2012) GenAlEx 6.5: genetic analysis in Excel. Population genetic software for teaching and research-an update. Bioinformatics 28(19):2537-2539

Peery MZ, Kirby R, Reid BN, Stoelting R, Doucet-Bëer E, Robinson S, Vásquez-Carillo C, Pauli JN, Palsbøll PJ (2012) Reliability of genetic bottleneck tests for detecting recent population declines. Mol Ecol 21:3403-3418

Pinzón JH, Sampayo E, Cox E, Chauka LJ, Chen CA, Voolstra CR et al. (2013) Blind to morphology: genetics identifies several widespread ecologically common species and few endemics among Indo-Pacific cauliflower corals (Pocillopora, Scleractinia). J Biogeogr 40(8):1595-1608

Prasetia R, Sinniger F, Hashizume K, Harii S (2017) Reproductive biology of the deep brooding coral Seriatopora hystrix: implications for shallow reef recovery. PLoS ONE 12(5):e0177034

Pritchard J, Stephens M, Donnelly P (2000) Inference of population structure using multilocus genotype data. Genetics 155(2):945-959

Ramanantsoa JD, Penven P, Krug M, Gula J, Rouault M (2018) Uncovering a new current: The Southwest Madagascar Coastal Current. Geophys Res Lett 45(4):1930-1938

Ratsimbazafy HA, Kochzius M (2018) Restricted gene flow among Western Indian Ocean populations of the mangrove whelk Terebralia palustris (Linnaeus, 1767) (Caenogastropoda: Potamididae). J Molluscan Stud 84:163-169

Richards ZT, Berry O, van Oppen MJH (2016) Cryptic genetic divergence within threatened species of Acropora coral from the Indian and Pacific Oceans. Conserv Genet 17:577-591

Ridgway T, Riginos C, Davis J, Hoegh-Guldberg O (2008) Genetic connectivity patterns of Pocillopora verrucosa in southern African Marine Protected Areas. Mar Ecol Prog Ser 354:161-168

Roberts CM, Shepherd ARD, Ormond RFG (1992) Large-scale variation in assemblage structure of Red-Sea butterflyfishes and angelfishes. J Biogeogr 19(3):239-250

Rumisha C, Huyghe F, Rapanoel D, Mascaux N, Kochzius M (2017) Genetic diversity and connectivity in the East African giant mud crab Scylla serrata: Implications for fisheries management. PLoS ONE 12(10):e0186817

Schleyer MH, Celliers L (2000) A survey of the coral reefs at Ilha Caldeira in the Segundas Archipelago, Mozambique, and an assessment of the marine environment impacts of a proposed heavy minerals mine. South African Association for Marine Biological Research, vol 190, Durban, 1-18

Schleyer MH, Celliers L (2005) The coral reefs of Bazaruto Island, Mozambique, with recommendations for their management. West Indian Ocean J Mar Sci 4:227-236

Schmidt-Roach S, Miller KJ, Lundgren P, Andreakis N (2014) With eyes wide open: a revision of species within and closely related to the Pocillopora damicornis species complex (Scleractinia; Pocilloporidae) using morphology and genetics. Zool J Linn Soc 170(1):1-33
Schott F, McCreary J (2001) The monsoon circulation of the Indian Ocean. Prog Oceanogr 51(1):1-123

Shearer TL, Coffroth MA (2008) Barcoding corals: limited by interspecific divergence, not intraspecific variation. Mol Ecol Resour 8(2):247-255

Sheets EA, Warner PA, Palumbi SR (2018) Accurate population genetic measurements require cryptic species identification in corals. Coral Reefs 37(2):549-563

Siddall M, Rohling EJ, Almogi-Labin A, Hemleben C, Meischner D, Schmelzer I et al. (2003) Sea-level fluctuations during the last glacial cycle. Nature 423(6942):853-858

Sofianos SS, Johns WE (2003) An Oceanic General Circulation Model (OGCM) investigation of the Red Sea circulation: 2. Threedimensional circulation in the Red Sea. J Geophys Res Oceans 108(C3): 15

Souter P, Grahn M (2008) Spatial genetic patterns in lagoonal, reefslope and island populations of the coral Platygyra daedalea in Kenya and Tanzania. Coral Reefs 27(2):433-439

Souter P, Henriksson O, Olsson N, Grahn M (2009) Patterns of genetic structuring in the coral Pocillopora damicornis on reefs in East Africa. BMC Ecol 9(19):13

Spalding MD, Fox HE, Halpern BS, McManus MA, Molnar J, Allen GR et al. (2007) Marine ecoregions of the world: a bioregionalization of coastal and shelf areas. Bioscience 57(7):573-583

Spöri Y, Flot JF (2020) HaplowebMaker and CoMa: two web tools to delimit species using haplowebs and conspecificity matrices. Methods Ecol Evol. https://doi.org/10.1111/2041-210X.13454

Stephens M, Scheet P (2005) Accounting for decay of linkage disequilibrium in haplotype inference and missing-data imputation. Am J Hum Genet 76(3):449-462

Stephens M, Smith NJ, Donnelly P (2001) A new statistical method for haplotype reconstruction from population data. Am J Hum Genet 68(4):978-989

Underwood JN, Smith LD, van Oppen MJH, Gilmour JP (2007) Multiple scales of genetic connectivity in a brooding coral on isolated reefs following catastrophic bleaching. Mol Ecol 16 (4):771-784

Underwood JN, Smith LD, van Oppen MJH, Gilmour JP (2009) Ecologically relevant dispersal of corals on isolated reefs: implications for managing resilience. Ecol Appl 19(1):18-29

van der Ven RM, Triest L, De Ryck DJR, Mwaura JM, Mohammed MS, Kochzius M (2016) Population genetic structure of the stony coral Acropora tenuis shows high but variable connectivity in East Africa. J Biogeogr 43(3):510-519

van Oosterhout C, Hutchinson WF, Wills DPM, Shipley P (2004) MICRO-CHECKER: software for identifying and correcting genotyping errors in microsatellite data. Mol Ecol Notes 4(3):535-538

van Oppen MJH, Bongaerts P, Underwood JN, Peplow LM, Cooper TF (2011) The role of deep reefs in shallow reef recovery: an assessment of vertical connectivity in a brooding coral from west and east Australia. Mol Ecol 20(8):1647-1660

van Oppen MJH, Gates RD (2006) Conservation genetics and the resilience of reef-building corals. Mol Ecol 15:3863-3883

van Oppen MJH, Lutz A, De'ath G, Peplow L, Kininmonth S (2008) Genetic traces of recent long-distance dispersal in a predominantly self-recruiting coral. PLoS ONE 3(10):e3401

Veron JEN (2000) Corals of the world. Australian Institute of Marine science, Townsville

Vogler C, Benzie J, Lessios H, Barber PH, Wörheide G (2008) A threat to coral reefs multiplied? Four species of crown-of-thorns starfish. Biol Lett 4(6):696-699

Vollmer SV, Palumbi SR (2002) Hybridization and the evolution of reef coral diversity. Science 296:2023-2025

Waits LP, Luikart G, Taberlet P (2001) Estimating the probability of identity among genotypes in natural populations: cautions and guidelines. Mol Ecol 10(1):249-256 
Warner PA, van Oppen MJH, Willis BL (2015) Unexpected cryptic species diversity in the widespread coral Seriatopora hystrix masks spatial-genetic patterns of connectivity. Mol Ecol 24(12):2993-3008

Weir BS, Cockerham CC (1984) Estimating $F$-statistics for the analysis of population-structure. Evolution 38(6):1358-1370
Wilkinson C (2002) Status of coral reefs of the world. Coral Reef Monitoring Network, Townsville

Wörheide G, Epp LS, Macis L (2008) Deep genetic divergences among Indo-Pacific populations of the coral reef sponge Leucetta chagosensis (Leucettidae): founder effects, vicariance, or both? BMC Evol Biol 8:24 